\title{
Technological Progress and Average Job Matching Quality*
}

\author{
Mário Centeno ${ }^{\dagger}$, Márcio V. Corrêa ${ }^{\ddagger}$
}

\author{
Contents: 1. Introduction; 2. Theoretical Model; 3. Technological Progress and Average Job \\ Matching Quality; 4. Conclusions. \\ Keywords: Job Creation; Job Destruction; Technological Progress. \\ JEL Code: J64; 033; 049.
}

Our objective is to study, in a labor market characterized by search frictions, the effect of technological progress on the average quality of job matches. For that, we use an extension of Mortensen and Pissarides (1998) and obtain as results that the effects of technological progress on the labor market depend upon the initial conditions of the economy. If the economy is totally characterized by the presence of low-quality job matches, an increase in technological progress is accompanied by an increase in the quality of jobs. In turn, if the economy is totally characterized by the presence of high-quality job matches, an increase in the technological progress rate implies the reverse effect. Finally, if the economy is totally characterized by the presence of very highquality jobs, an increase in the technological progress rate implies an increase in the average quality of the job matches.

O objetivo deste artigo é o de estudar, em um mercado de trabalho caracterizado por fricções, os efeitos do progresso tecnológico sobre a qualidade média das parcerias produtivas. Para tal, utilizamos uma extensão do modelo de Mortensen and Pissarides (1998) e obtivemos, como resultados, que os efeitos de variações na taxa de progresso tecnológico sobre o mercado de trabalho dependerão das condições da economia. Se a economia for totalmente caracterizada pela presença de parcerias produtivas de baixa qualidade, um aumento na taxa de progresso tecnológico vem acompanhado por um aumento na qualidade médias das parcerias produtivas. Por sua vez,

\footnotetext{
* We thank an anonymous referee, Miguel St. Aubyn, Tiago Cavalcanti, Antonio Menezes and Carlos Eugênio da Costa for helpful suggestions.

†Banco de Portugal, Av. Almirante Reis, 716, 1150-012 Lisbon, Portugal and ISEG, Universidade Técnica de Lisboa, Rua do Quelhas, 6, 1200-781 Lisbon, Portugal. E-mail: mario. centeno@bportugal.pt

${ }_{\ddagger}$ CAEN, Universidade Federal do Ceará, Av. da Universidade, 2700, 60020-181 Fortaleza, Brazil. E-mail: marciovcorrea@gmail. com
} 
se a economia for totalmente caracterizada pela presença de parcerias produtivas de alta qualidade, um aumento na taxa de progresso tecnológico gera um efeito inverso. Finalmente, se a economia for totalmente caracterizada pela presença de parcerias produtivas de muito alta qualidade, um aumento na taxa de progresso tecnológico virá acompanhado de uma elevação na qualidade média dos empregos.

\section{INTRODUCTION}

A labor market model has to be able to explain several aspects related to job creation and job destruction dynamics. Davis et al. (1996) for example, found that job creation and destruction flows are typically high, heterogeneous, and asymmetric and that the job destruction process is the one which normally dictates job changes. ${ }^{1}$ In other words, according to these authors, a labor market model should explain that regardless of the current economic state, job creation and job destruction flows are normally high, distinct for different sectors and periods, and that the destruction process is the main responsible for the changes in job match characteristics.

Apart from these facts, the authors also argued that a labor market model should be able to explain that the best job matches present lower creation and destruction rates and that break ups are in most cases, provoked by worker decisions if the matches are of high quality and by firms if they are of low quality.

Based on these empirical evidences, ${ }^{2}$ several studies were conducted in an attempt to explain some of these facts, determining their consequences on particular aspects of the labor market, such as average job quality evolution.

Caballero and Hammour (1994), for example, formalized the idea that recessions are periods of high job destruction and low job creation flows, and that if considered together, the result should be an increase in average match quality. According to these authors during recession there is a process of elimination of the less productive jobs from the market. The idea was that these periods were characterized by a cleansing effect in which the least efficient jobs would be the first ones to be eliminated and only the most productive jobs would remain in the market. ${ }^{3}$ However, although Caballero and Hammour showed the consequences of recession on average job quality, their results do not have empirical support, as Bowlus (1995) demonstrated.

Bowlus found in and empirical analysis of job quality evolution in the US that what is happening is precisely the opposite of what Caballero and Hammour suggested. In other words, Bowlus observed that recessions are not only periods of no improvement, but also of actual deterioration in the average quality of matches. ${ }^{4}$

Based on these findings, Barlevy (2002) considered the effects of recessions on job destruction, in addition to the effects of recessions on job creation dynamics. This author argued that considering on-the-job search, we would have the creation of an additional effect, empirically stronger than the one proposed by Caballero and Hammour, which he denominated sullying effect.

The idea defended by Barlevy in his theoretical model was that recessions were periods characterized by low quality job creation. In this way, if these effects overcome those generated by destruction dynamics, we would have a reduction, and not an improvement, in the average quality of job matches.

\footnotetext{
${ }^{1}$ Rogerson et al. (2005) argues that the job creation process is the one that drives job changes.

${ }^{2}$ Davis et al. (1996) approached the facts for the U.S. economy. See Mortensen and Pissarides (1999) for OECD countries.

${ }^{3}$ Papers by Hall (1991), Mortensen and Pissarides (1994) and Gomes et al. (2001) support this argument.

${ }^{4}$ Davis et al. (1996) also found these empirical facts in the US, while Fernandez (2004) verified it in Spain.
} 
However, although Barlevy explained the reduction in the average quality of jobs during recessions, the proposed dynamics go against the stylized fact proposed by Davis, Haltiwanger and Schuh, in which the job destruction process is considered to be the main responsible for the characteristics of existing jobs in the market.

In order to address this issue, this paper has as its principal goal the study of the impact of the technological progress rate on the average quality of job matches, considering the greater importance of destruction dynamics in matching quality determination and that the job destruction process is determined by workers, if the matches are of high quality, and by firms, if they are of low quality.

The proposed model is more closely related to the creative destruction technological progress model of Mortensen and Pissarides (1998), with the introduction of heterogeneity, both in job matching quality and in the worker-firm information set. The idea behind this last aspect is to consider that the workerfirm information sets, which are responsible for job quality personal evaluation, do not coincide.

We will see that these simple changes are enough to create heterogeneity in the job destruction process and a greater relative importance of destruction dynamics in basic job aspects, as argued by Davis, Haltiwanger and Schuh. We will also see that for specific parameters and initial conditions, it is possible to create either the cleansing or the sullying effect proposed by Caballero and Hammour (1994) and Barlevy (2002).

The intuition of the model is that, for the low quality match group, an increase in the technological progress rate implies both an increase in the job destruction flow as well as a reduction in job creation dynamics. Taking these two flows into consideration, we will have an increase in the average job quality in this interval. In turn, for high-quality matches, both effects will not imply an increase, but rather, a reduction in average quality. Therefore, considering both previous scenarios, the effect of higher growth rates on the average job quality will depend on the relative dimension of high versus low job quality intervals after the increase in the technological progress rate.

However, although the present model is compatible with results obtained by Caballero and Hammour (1994) and Barlevy (2002), two aspects will differentiate it from these models. Firstly, in the Barlevy model, the sullying effect is the result of a high-low quality job creation, while in our model this effect is obtained via job destruction dynamics. Secondly, in these models the idea of quality is closely related to the notion of job match productivity, while an innovation of our model is that the concept of quality is associated to the idea of non-monetary job attributes. In other words, according to Caballero and Hammour (1994) and Barlevy (2002), an improvement in job matching average quality is equivalent to an increase in the average match productivity, while in our model an improvement in the average quality implies a qualitative average improvement, not necessarily implying a change in average productivity. In this way, the heterogeneity proposed by the model is equivalent to the differences in match attributes, which create value, both for the worker and for the firm, without implying any changes in match productivity. ${ }^{5}$

This paper is organized as follows: in Section 2 we will develop a theoretical model, while in the Section 3 we will see the main results obtained concerning the effect of technological progress rate changes on job matching average quality. In Section 4 we will analyze our main conclusions.

\section{THEORETICAL MODEL}

In this section we will present the characteristics of our theoretical model. The modeled scenario is based on Mortensen and Pissarides' (1998) technological progress model with the inclusion of heterogeneity, both for matching quality and the worker-firm information set related to expected job quality evaluation.

\footnotetext{
${ }^{5}$ Hamermesh (1997) use a similar definition of job quality to study immigration.
} 
Agents and Preferences. The economy is formed by a constant population of workers and a great number of firms that together give rise to the productive activity. Firms and workers are heterogeneous, neutral to risk, and maximize the expected present value discounted of their earnings, subject to the information available at a given moment.

Let's consider transferable utility, the existence of a perfect capital market and that workers and firms discount the future at an exogenous and constant rate $r$.

Each firm has only one job position, which can be occupied or not, and employs only one worker at a time. In turn, each worker can be employed in only one job per period or be unemployed.

Search and Production. Before the beginning of production, firms and workers undertake an individual, independent and expensive search process. Let $P(t) c$ be the search cost for firms, where $P(t)=e^{g t}$ represents a common growth factor.

Assume that there is no on-the-job search and that the quantity of job matches formed per period is given by function $m(v, u)$ non-negative, concave, homogeneous of degree one and increasing in its two arguments, where $v$ represents the vacancy rate and $u$, the number of unemployed workers in the economy per period.

Unemployed workers gain employment status according to a rate $\theta q(\theta)$, where $\theta$ is the ratio of $v$ and $u$, while a job vacancy becomes occupied at a rate $q(\theta){ }^{6}$

Before production begins, firms fix their technology at a cost $P(t) K$. Assume that this is irreversible and that it is in the technological frontier at the moment the match is formed.

Note that with this technological progress format, since a job match cannot be updated once it's created, its production will remain constant at its initial level, $\tau$.

Suppose that filled positions can be destroyed due to an idiosyncratic shock that follows a Poisson Process with arrival rate $\lambda$, which aims at capturing, for example, any negative exogenous events that affect the productivity of a particular job match.

Observe from the two previous conditions, that a particular job match can be destroyed due to an aggregate shock, represented by larger growth rates that affect the obsolescence rate of all existing job matches, or due to a specific shock, which affects a particular job match individually.

Every occupied match has two components that affect its value for the firm. The first one is given by $P(\tau) x$, and represents the labor production generated by a job match formed in $\tau$. Up to now, the model is exactly that of Mortensen and Pissarides (1998). The second one is represented by the term $\alpha$ and aims at capturing differences in the quality of job matches created at the same moment $\tau$.

Assume that $\alpha$ is time invariant and uniquely determined at the moment in which the match is formed, in an exogenous and independent way from a particular distribution function $G(\alpha)$. Suppose it's also an experience good, that is, it can only be known after the beginning of production, ${ }^{8}$ and that the firm and the worker have different information sets in the evaluation of the expected value of $\alpha .^{9}$

If apart from the previous conditions, we consider that at any time both firms and workers can terminate an ongoing job match, that is, they can break up the partnership and return to the search

\footnotetext{
${ }^{6}$ Note that $q(\theta)=m\left(\frac{u}{v}, 1\right)$ and $\theta q(\theta)=\frac{m(v, u)}{v} \frac{v}{u}$.

${ }^{7}$ We will consider that although a higher matching quality does not affect job productivity, it affects the effective discount rate. In other words, we will consider that the higher the job quality, the lower the value of the match that will be discounted, as workers and firms prefer good jobs to lower quality ones. This is the mainly the basic modification in workers and firms value functions, given the introduction of non-monetary job attributes (does not affect productivity) in a creative destruction model of growth. See Mortensen and Pissarides (1998) and Hamermesh (1997) for details.

${ }^{8}$ Notice that the condition that $\alpha$ is an experience good implies that all meetings will create job matches, since there is no rejection before production starts.

${ }^{9}$ The idea of this condition is to consider that workers and firms do not calculate the expected value of $\alpha$ in the same way, when deciding to destroy a job match.
} 
process in order to find a new partner, we have that jobs created at each particular moment will have distinct obsolescence periods, according to their quality and the technological progress rate.

The technological progress dynamics of creative destruction type implies the existence of a constant process of creation and destruction of job matches due to the hypothesis that only the most-recently jobs have the highest level of technology. The only way of updating an already existing job match is via the destruction of this relationship and the formation of a new one.

Note that the idea behind the previous condition on $\alpha$ is that before the formation of a job match, two workers (firms) are seen in an identical way by the firms (workers) and only after production starts does the quality of the job match start to be revealed.

Suppose, in order to facilitate main model result presentation, that $\alpha$ is defined in the interval:

$$
\left(0, \frac{r}{1-\lambda}\right)
$$

Wages. If a productive match is destroyed by the worker, by the firm or even in an exogenous way, both the worker and the firm have to pay the costs related to the return to the search process. In this way, a productive match generates a surplus that has to be distributed among the two parties. Let's suppose, as standard in job search theory, that this division is determined by the Generalized Nash Bargain Process between the firm and the worker, where $\beta$ represents worker bargaining power.

Equilibrium. Let $V(t)$ represent the present discounted value for a firm of the expected gains from a job vacancy created at $t, J(t, \tau, \alpha)$, the present discounted value for a firm of the expected gains associated to a job created at $\tau$, with quality $\alpha$, and occupied in period $t, U(t)$ the present discounted value for the worker of the expected gains associated with the unemployment, and $W(t, \tau, \alpha)$ stands for present discounted value for the worker of the expected gains associated to a job created at $\tau$, with quality $\alpha$, in period $t$. Thus we have:

$$
\begin{aligned}
& r V(t)=-P(t) c+q(\theta)\left[\left(1+\alpha_{W}^{e}\right) W(t, t, \alpha)-V(t)-P(t) K\right]+\dot{\bullet}^{(t)} \\
& r J(t, \tau, \alpha)=\operatorname{Max}\{P(\tau) x-w(t, \tau, \alpha)+\alpha J(t, \tau, \alpha)-\lambda[(1+\alpha) J(t, \tau, \alpha)-V(t)] \\
& +\quad J(t, \tilde{\tau}, \alpha) ; r V(t)\} \\
& r U(t)=P(t) b+\theta q(\theta)\left[\left(1+\alpha_{W}^{e}\right) W(t, t, \alpha)-U(t)\right]+\stackrel{\bullet}{U(t)} \\
& r W(t, \tau, \alpha)=\operatorname{Max}\{w(t, \tau, \alpha)+\alpha W(t, \tau, \alpha)-\lambda[(1+\alpha) W(t, \tau, \alpha)-U(t)] \\
& +W(\dot{t}, \tau, \alpha) ; r U(t)\}
\end{aligned}
$$

where $\alpha_{F}^{e}$ represents the expected job match quality for the firm; $w(t, \tau, \alpha)$ the worker's wage rate, at a moment $t$, in a match formed at $\tau$, with quality $\alpha ; P(t) b$ is the job opportunity cost for the worker, while the last terms represent, respectively, time variations in $V(t), J(t, \tau, \alpha), U(t)$ and $W(t, \tau, \alpha)$. We assume that $\alpha_{F}^{e}$ and $\alpha_{W}^{e}=\alpha^{e}+\xi$, where $\xi$ is a small term that represents deviations in worker and firm expectations in regards to $\alpha^{e}$.

Observe that with these function value specifications, the job quality component enters in a proportional manner in $W(t, \tau, \alpha)$ and $J(t, \tau, \alpha)$. Thus, the term associated to job quality depends on $\alpha$ and on the present discounted value of expected gains associated to an occupied job for the worker 
and for the firm, of $W(t, \tau, \alpha)$ and $J(t, \tau, \alpha)$ respectively. The main reason behind this formulation is to consider that the effects created by the quality of a match, directly affect worker and firm job matching valuations. In other words, we are considering that the higher the job matching quality, the less it will be discounted, since this is preferred to a lower quality match.

Note from expression (2), that when a vacancy is occupied, it will generate a gain given by the difference between the value of a vacancy and the value of an occupied job, plus the gains associated to the expected quality of the match to be formed. In turn, we can verify from expression (4) that once a worker is employed, he will have a gain given by the difference between employment and unemployment values, plus the gains associated to the expected quality of the match to be formed.

Continuing with equilibrium characterization, we will assume that $r+\lambda-\alpha(1-\lambda)>g$ and $b<x$, in a way that the effective discount rate is positive and that there are strictly positive advantages in the formation of a job match, according to results from job search theory.

Considering the usual hypothesis of free entry, we have from (2), that

$$
\left(1+\alpha_{F}^{e}\right) J(t, t, \alpha)=\left[\frac{P(t) c}{q(\theta)}+P(t) K\right]
$$

where we can see that the expected value of a new job match is equal to the sum of the cost of occupying a vacancy expressed in terms of the rate at which this vacancy is occupied, and the cost of creating this new vacancy.

Now, as usual in job search models, occupied jobs generate a return that is greater than the sum of the expected returns from firms and workers in the searching process. In this way, if firms and workers separate, each will have to go though a process of search before starting a productive partnership. In this way, a job match generates an economic rent that must be divides between workers and firms. Wages need to share this surplus. Then, $w(t, \tau, \alpha)$ satisfies: ${ }^{10}$

$$
\beta[J(t, \tau, \alpha)-V(t)]=(1-\beta)[W(t, \tau, \alpha)-U(t)]
$$

Using expressions (3) - (7), and assuming $\alpha_{F}^{e}=\alpha_{W}^{e}=\alpha^{e}$, the wage rate at that moment $t$, in a match formed at $\tau$, with quality $\alpha$ is given by:

$$
w(t, \tau, \alpha)=\beta P(\tau) x+(1-\beta) P(t) \delta(\theta(t), \alpha) \omega(\theta(t))
$$

where $\delta(\theta(t), \alpha)$ and $\omega(\theta(t))$ are given by: ${ }^{11}$

$$
\begin{gathered}
\delta(\theta(t), \alpha)=\frac{r-\alpha(1-\lambda)}{r-\theta q(\theta) \alpha^{e}} \\
\omega(\theta(t))=b+\left(\frac{\beta}{1-\beta}\right)[c \theta+k \theta q(\theta)]
\end{gathered}
$$

Note that we are supposing that workers and firms bargain and choose the expected value of $\alpha_{F}^{e}$ and $\alpha_{W}^{e}$ in the wage bargaining process. We can also observe from the previous expressions that the wage rate is formed by two terms. The first is associated to the worker's productivity, and the second is related to his outside options.

We can also observe from the previous expression that a greater technological progress rate, the greater will be the worker's wage rate, due to the growth verified in the term related to his outside option, and that a greater $\alpha$ shall result in a lower wage growth, for a given technological progress rate.

\footnotetext{
${ }^{10}$ See Osborne and Rubinstein (1990) for the foundations of Nash Bargaining. See Rogerson et al. (2005) for the use of Generalized Nash Bargaining in the equilibrium unemployment theory.

${ }^{11}$ To simplify the presentation of the model basic results, assume that terms defined in expression (9) are always positive.
} 
Note also that greater $\alpha^{e}$ and $\theta$ values shall result in a higher wage growth for a given technological progress rate. The reason for the first effect is that as $\alpha^{e}$ increases, the expected quality obtained in a new job match will also be higher, giving way to an increase in the worker's wage rate in his current job. In turn, the greater $\theta$ is, the greater the ratio of vacant jobs for unemployed workers will become, which implies higher wage rates, due to the congestion effect. ${ }^{12}$

Another interesting aspect that we observe is that worker outside options increase at the technological progress rate, while the wage rate increases at a lower rate. As a consequence, there will be a moment $T^{W}$ in which the worker will terminate his current match, as his outside options become greater than his wage.

In turn, as worker wages grow at a rate proportional to the technological progress rate, while job productivity remains constant, there will be a moment $T^{F}$ where worker productivity shall be lower than his wage, implying the destruction of the job match by the firm.

Thus, $T^{W}$ and $T^{F}$ represent the moments at which the worker and the firm destroy the job match, respectively. Using expressions (3) to (5), together with equation (8) and conditions $\alpha_{F}^{e}=\alpha^{e}+\xi$ and $\alpha_{W}^{e}=\alpha^{e}-\xi$, we have that $T^{W}$ and $T^{F}$ are determined by:

$$
\begin{aligned}
J(t, \tau, \alpha)= & \underset{T^{F}}{\operatorname{Max}}\left\{\int_{t}^{\tau+T^{F}}\left[(1-\beta) P(\tau) x-(1-\beta) P(s) \delta_{F}(\theta(s), \alpha) \omega(\theta(s))\right]\right. \\
& \left.e^{-[r+\lambda-\alpha(1-\lambda)](s-t)} . d s\right\} \\
W(t, \tau, \alpha)= & \operatorname{Max}_{T^{W}}\left\{\int _ { t } ^ { \tau + T ^ { W } } \left[\beta P(\tau) x+(1-\beta) P(s) \delta_{W}(\theta(s), \alpha) \omega(\theta(s))\right.\right. \\
& \left.\left.-P(s) \varphi(\theta(s), \alpha) \delta_{F}(\theta(s), \alpha) \omega(\theta(s))\right] e^{-[r+\lambda-\alpha(1-\lambda)](s-t)} . d s\right\}
\end{aligned}
$$

where

$$
\varphi(\theta(s), \alpha)=\frac{r-\lambda}{r-\alpha(1-\lambda)}
$$

Note that the terms $\delta_{W}$ and $\delta_{F}$ are identical to $\delta$, except that in the denominator we have, respectively, $r-\theta q(\theta) \alpha_{W}^{e}$ and $r-\theta q(\theta) \alpha_{F}^{e}$, and we are supposing that although worker bargain wages with $\alpha^{e}$, they use $\alpha_{F}^{e}$ and $\alpha_{W}^{e}$ in the destruction dynamics. If $\alpha_{F}^{e}=\alpha_{W}^{e}$ we would have $T^{F}$ and $T^{W}$.

We can observe from the previous expressions that $T^{F}$ and $T^{W}$ coincide with the moment where the value of an occupied job is zero for the firm, and with the moment when employment value equals the value of unemployment for the worker respectively.

Considering $\tau=t$ in the previous expressions, the first order conditions of the previous optimization problems are respectively: ${ }^{13}$

$$
\begin{gathered}
(1-\beta) x-(1-\beta) \delta_{F} \omega e^{g T^{F}}=0 \\
\beta x-\omega e^{g T^{W}}\left[\varphi \delta_{F}-(1-\beta) \delta_{W}\right]=0
\end{gathered}
$$

\footnotetext{
${ }^{12}$ The idea behind the congestion effect is that as $\theta$ grows, the probability of a firm occupying a vacancy decreases, while the probability of an unemployed worker finding a vacancy increases.

${ }^{13}$ Notice that in order to have strictly positive $T^{F}$ and $T^{W}, x>\delta_{F} \omega>0$ and $\beta x>\left[\varphi \delta_{F}-(1-\beta) \delta_{W}\right]>0$.
} 
Observe from the two previous expressions, that the optimal moments $T^{W}$ and $T^{F}$ diminish with higher values of $\theta$. The reason for this behavior is that a larger $\theta$ will result in higher worker wages, implying a reduction in $T^{F}$. On the other hand, a greater $\theta$ will result in higher outside options for the worker, which implies a lower $T^{W}$.

We can also observe that $T^{W}$ and $T^{F}$ decrease with higher technological progress rates.

Finally, we can observe from these expressions that $T^{W}$ diminishes with a greater $\alpha$, while $T^{F}$ grows. The reason for this is that higher $\alpha$ values result in lower wage rate growths if compared to the improvement seen in worker outside options, which will make job match obsolescence faster for the worker. On the other hand, greater $\alpha$ values make job match obsolesce slower for the firm.

Observe also that a greater $\alpha$ means a higher present discounted value of the expected gain given by the job match for both the worker and the firm. However, as time goes by, a high quality job will lose its value faster for the worker than for the firm if compared to a low quality job.

Now, let $\alpha_{I}$ be the value of $\alpha$ that makes $T^{F}=T^{W}$. If $\alpha$ is given by $\alpha_{I}$ we will have $T^{F}=T^{W}$. However, as $\alpha$ is lower than $\alpha_{I}$ we will have $T^{F}<T^{W}$ and, in this case, the firm will be the agent to destroy the job match. In turn, if $\alpha$ is greater than $\alpha_{I}$ we will have the opposite scenario, that is, we will have $T^{F}>T^{W}$ and in this case, the worker will be the agent to destroy the job match. In other words, for different values of $\alpha$ we will have different agents initiating the destruction dynamics. If $\alpha$ is lower than $\alpha_{I}$ the expression that determines $T^{W}$ loses its importance in the equilibrium characterization, since the destruction of the job match will be $T^{F}$, a moment that happens earlier than $T^{F}$. In turn, if $\alpha$ is above $\alpha_{I}$ the expression that determines $T^{F}$ loses its importance in the equilibrium characterization, since the moment of destruction will be $T^{W}$, a moment that happens earlier than $T^{F}$.

Continuing with the equilibrium characterization, when considering $\tau=t, J(t, t, \alpha)=P(t) J$ and the optimum $T^{F}$ in (11), we have that

$$
J=(1-\beta) \int_{0}^{T_{F}^{F}}\left[x-\delta_{F} \omega e^{g t}\right] e^{-[r+\lambda-\alpha(1-\lambda)] t} d t
$$

represents the value of a job created at moment $t$ which will survive, if there is no exogenous destruction, up to moment $T^{F}$.

Using $J(t, t, \alpha)=P(t) J$ in (6), we have that (16) and

$$
J=\frac{1}{\left(1+\alpha_{F}^{e}\right)}\left[\frac{c}{q(\theta)}+K\right]
$$

determines job creation dynamics.

These expressions tell us that expected firm gains from a new job match must equal expected costs related to the creation of a new vacancy.

Having characterized job creation and destruction dynamics, we must now obtain the expression that sets equilibrium unemployment rate. The job creation flow, at moment $t$, is given by:

$$
J C=\theta q(\theta) u(t)
$$

where $u(t)$ represents the unemployment rate, while the job destruction flow, at moment $t$, is given by:

$$
J D=\lambda[1-u(t)]+e^{-\lambda T^{F}} F\left(\alpha_{I}\right) J C+e^{-\lambda T^{W}}\left[1-F\left(\alpha_{I}\right)\right] J C
$$

where the term $\lambda[1-u(t)]$ represents the job destruction flow coming from the exogenous process and $e^{-\lambda T}$ measures the fraction of the job creation flow that survives up to the destruction moments $T^{F}$ or $T^{W}$, in accordance to the job match quality. Therefore, from the two last expressions, we have that the equilibrium unemployment rate is given by: 


$$
u=\frac{\lambda}{\lambda+\theta q(\theta)\left\{1-e^{-\lambda T^{F}} F\left(\alpha_{I}\right)-e^{-\lambda T^{W}}\left[1-F\left(\alpha_{I}\right)\right]\right\}}
$$

Observe from expression (20) that the further $\alpha$ is from $\alpha_{I}$, above or below, the faster the job match destruction will be as $T^{F}$ or $T^{W}$ diminish, according to the direction in which $\alpha$ moves, leading to an increase in the equilibrium unemployment rate. ${ }^{14}$ Thus, as match quality becomes more distant from quality $\alpha_{I}$, even in the direction of better qualities, the result will be an increase in unemployment rate. The basic reason for a higher job destruction rate in better quality job matches is that these types of jobs are less sensitive to what happens in the market. In this way, although a good quality job matching is preferable to a lower quality one, these jobs will be quickly destroyed, since worker wage rates in these jobs do not follow average wage rate growth.

In this way, if $\alpha_{0}<\alpha_{1}<\alpha_{I}$ and $\alpha_{a}>\alpha_{b}>\alpha_{I}$ then, job matches with productivity $\alpha_{0}$ and $\alpha_{a}$ will be firstly destroyed, if compared to jobs with productivity $\alpha_{1}$ and $\alpha_{b}$, respectively.

Definition: Given the distribution of job match qualities, a steady-state equilibrium for this economy is a four-tuple $\left(\theta, T^{j}, w(\tau, t), u\right)_{j=F, i f \alpha<\alpha_{I} ; W, i f \alpha>\alpha_{I}}$ such that (8),(14),(15),(17) and (20) are satisfied.

The equilibrium is recursive, for a given $\alpha$, the expressions (14) - (17) determine the equilibrium in the $T-\theta$ space. Then, we can use $T$ and $\theta$ to find wage rate and the equilibrium unemployment rate.

As the model developed up to now does not consider the reaction of an agent when the other party decides to destroy the job match, we will introduce the idea that the results of such an action can be so adverse that the agent affected by the destruction interferes in the process, avoiding the job match destruction. ${ }^{15}$

Now observe that in order to analyze the best agent response to the destruction decision of the other, we need to compare the value that this agent would receive if such a decision was not taken by the other party.

Now, as $\xi$ is the term that makes $\alpha_{W}^{e} \neq \alpha_{F}^{e}$ and that when considered in the job destruction dynamics, it makes $T^{F} \neq T^{W}$, considering it to be positive implies that the only case to analyze is $T^{F}<T^{W}$. In this way, following this pattern, at the moment $T^{F}$ (at which the firm decides to destroy the job match) employment value is given by:

$$
J\left(T^{F}, \tau, \alpha\right)=V\left(T^{F}\right)
$$

Proposition 1 Suppose that $T^{F}<T^{W}$. Thus, whenever the job match quality is given by $\alpha_{M}$, that satisfies

$$
\alpha_{M}<\frac{r}{1-\lambda}-\frac{P\left(T^{F}\right) \delta_{1} \omega}{(1-\lambda) W\left(T^{F}, T^{F}, \alpha\right)}
$$

it is more advantageous for the worker to keep the current job match.

Proof. The value of the unemployment option for the worker at moment $T^{F}$ is $U\left(T^{F}\right)=\frac{P\left(T^{F}\right) \delta_{W} \omega}{r-\alpha(1-\lambda)}$. Thus, whenever $W\left(T_{F}, \tau, \alpha\right)>U\left(T^{F}\right)$ it is advantageous for the worker to keep the present job match. Manipulating these last two expressions, we arrive at the expression that $\alpha_{M}$ must satisfy.

Now, if we consider that it is possible to isolate the best jobs within the group of poor-quality job matches, and that $r W\left(T^{F}, \tau, \alpha\right)>P\left(T^{F}\right) \delta_{1} \omega>0$, we have that $\alpha_{M}$ is defined in interval (1).

The intuition of the preceding proposition is the following: if at the moment in which a firm decides to destroy a job match, the value of the job for the worker is higher than his outside option, the worker

\footnotetext{
${ }^{14}$ Auer et al. (2004) also found this empirical relationship.

${ }^{15}$ Consider that we are assuming that there is no rigidity on downward wage movements in this scenario.
} 
Figure 1: Job Destruction Dynamics

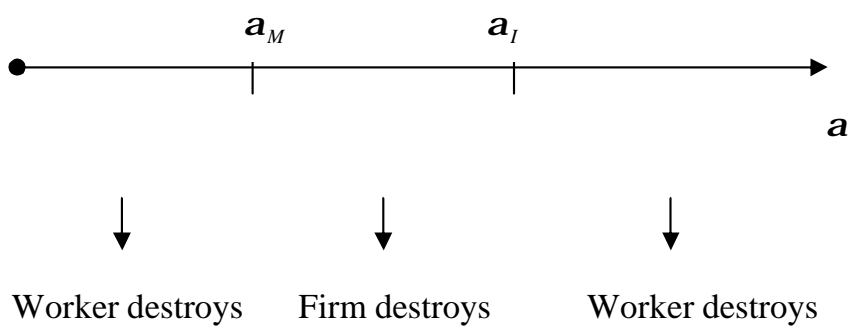

will react to job destruction by accepting lower wages. Now, as the value of the job at moment $T^{F}$ is higher than his outside option, we can expect that the worker will accept a wage rate reduction in order to keep his current job match. Thus, whenever the job match is defined in the previous interval, the job will not be destroyed at $T^{F}$.

Also notice that the higher $\xi$ is, the more probable it is that the worker reacts to job destruction.

Observe also that the worker will preserve a match with lower $\alpha$ because at that moment, it is better than a high quality one - although it's not good quality, it pays high wages.

Therefore, if the job match belongs to the lowest quality subgroup among those of lower quality, it will not be destroyed at $T^{F}$, but will rather last until the moment $T^{W}$. In turn, if the job has quality between $\alpha_{M}$ and $\alpha_{I}$, it will be destroyed at $T^{F}$, as we can see in figure 1 .

\section{TECHNOLOGICAL PROGRESS AND AVERAGE JOB MATCHING QUALITY}

In this section we will examine the effects of technological progress rate changes over job matches average quality.

First of all, assume that the economy is completely characterized by job matches defined in the quality interval $\alpha_{M}<\alpha<\alpha_{I}$. In this case, we have that $T$ is determined by expression (14) and we can observe that as $g$ grows $T^{F}$ falls, or in other words, as the technological progress rate grows, firms will destroy existing job matches more rapidly. The reason for this behavior is that the greater $g$ is, the higher will be the wage growth, and as these are low quality jobs, they will become obsolete more quickly, leading to their destruction.

At the same time, in regards to job creation dynamics, as $g$ grows, the process will become less pronounced, because these new jobs will pay higher wages.

Hence, we will have as a final result an increase in job destruction and a reduction in job creation dynamics. Now, as destruction occurs from the worst to the best job matches, the worst quality jobs will be the first to be destroyed, leading to an increase in the average quality of existing matches for the interval $\alpha_{M}<\alpha<\alpha_{I}$.

Also notice that if instead of an increase, there is a decrease in the technological progress rate, the result will be as before, an increase in average job match quality. The idea now is that we have a reduction in the job destruction process and a growth in job creation dynamics. However, the job creation flow would lead to the independent creation of job matches in the previous interval. In this way, we can expect no changes in job quality coming from the job creation side.

Furthermore, as destruction dynamics follow the same pattern, which means that the jobs with less quality are the first to be destroyed, we will again have an increase in job matches average quality.

Now consider the job matches defined in the interval $\alpha<\alpha_{M}$. In this case we will have $T$ determined by the expression (15) and as $g$ grows, $T^{W}$ falls, which means the worker wishes to destroy the 
job match more quickly. The reason now is that the wage rate does not respond to every increase in worker outside option, which leads him to destroy his current job match sooner.

In turn, on the job creation side, the results are identical to those previously obtained.

Thus, an increase in $g$ implies an increase in the job destruction flow and a reduction in job creation dynamics. However, there will be a difference in comparison to earlier results. As workers first destroy jobs with greater $\alpha$ followed by the jobs with smaller $\alpha$, the destruction process will generate opposite results. So we will have job matches being destroyed from the best to the worst ones, leading to a reduction in job matches average quality. Therefore, whenever we consider jobs defined in the interval $\alpha<\alpha_{M}$, the increase in job destruction will be followed by a worsening in job matches average quality.

Finally, for the jobs with quality defined in the interval $\alpha \geq \alpha_{I}$, the destruction moment is again given by the expression (15) and the effects of changes in the technological progress on average job match quality are identical to those previously obtained for the jobs defined in the interval $\alpha<\alpha_{M}$.

Bringing all previous results together, that is, considering all quality intervals, we can see that it is possible to obtain both an improvement and a decline in the aggregate quality of job matches. The final result will depend on both the job matches distribution and on the parameters related to the determination of $\alpha_{M}$ and $\alpha_{I}$.

\section{CONCLUSIONS}

The goal of this paper was to analyze job matches average quality behavior, bearing in mind empirical facts proposed by literature.

Earlier studies defended different arguments in regards to the effect of periods of low average quality growth. On one hand, it was argued that these periods were characterized by a cleansing effect, which implied an increase in job matching average quality. On the other hand, it was argued that these periods were not characterized by a cleansing effect, but rather by a sullying effect. Therefore, these periods were moments of job match quality reduction.

We saw that it is possible to obtain both the cleansing as well the sullying effect, depending on job match distribution and on parameters related to $\alpha_{M}$ and $\alpha_{I}$. The advanced idea is that variations in the technological progress rate create different dynamics in the job destruction process, depending on job match quality.

We demonstrated that two simple modifications in the technological progress model of creative destruction type of Mortensen and Pissarides (in order to allow the existence of stochastic job matches and perception differences on a new job match average quality by the involved agents) was enough to explain job average quality behavior, taking into account the fact that the destruction process must be the main responsible for this pattern and that depending on the job quality, we will have different agents affecting destruction dynamics.

\section{BIBLIOGRAPHY}

Auer, P., Efendioglu, U., \& Leschke, J. (2004). Active labour market policies around the world: Coping with the consequences of globalization. Employment Strategy Paper 2004/9, ILO, Geneva.

Barlevy, G. (2002). The sullying effect of recessions. The Review of Economic Studies, 69:65-96.

Bowlus, A. (1995). Matching workers and jobs: Cyclical fluctuation in match quality. Journal of Labor Economics, 13(2):335-50.

Caballero, R. J. \& Hammour, M. L. (1994). The cleansing effect of recessions. The American Economic Review, 84:1350-68.

Davis, S., Haltiwanger, J., \& Schuh, S. (1996). Job Creation and Job Destruction. The MIT Press, Cambridge. 
Fernandez, C. (2004). Job match quality throughout the business cycles in the spanish labor market. Documento de Trabajo 2004-01, FEDEA, Madrid.

Gomes, J., Greenwood, J., \& Rebelo, S. (2001). Equilibrium unemployment. Journal of Monetary Economics, 48:109-52.

Hall, R. (1991). Labor demand, labor supply, and employment volatility. Macroeconomics Annual, NBER.

Hamermesh, D. (1997). Immigration and the quality of jobs. NBER Working Paper 6195.

Mortensen, D. T. \& Pissarides, C. A. (1994). Job creation and job destruction in the theory of unemployment. The Review of Economic Studies, 61:733-53.

Mortensen, D. T. \& Pissarides, C. A. (1998). Technological progress, job creation and job destruction. Review of Economic Dynamics, 1:733-53.

Mortensen, D. T. \& Pissarides, C. A. (1999). New developments in models of search in the labor market. In Ashenfelter, O. \& Card, D., editors, Handbook of Labor Economics. Elsevier Science, Amsterdam.

Osborne, M. J. \& Rubinstein, A. (1990). Bargaining and Markets. Academic Press, Diego.

Rogerson, R., Shimer, R., \& Wright, R. (2005). Search-theoretic models of the labor market: A survey. Journal of Economic Literature, 43:959-88. 